\title{
Role of tiotropium in chronic obstructive pulmonary disease exacerbation
}

\author{
P. Pant, ${ }^{1}$ B. Yadav, ${ }^{2}$ G. M. Khan, ${ }^{2}$ R. Koju, ${ }^{1}$ R. Gurung, ${ }^{1}$ B. Pokharel, ${ }^{1}$ T. R. S. Bedi, ${ }^{1}$ R. K. Adkhari ${ }^{3}$ \\ ${ }^{1}$ Department of Internal Medicine, Kathmandu University School of Medical Sciences; ${ }^{2}$ Department of Pharmacy, Kathmandu \\ University, Dhulikhel, Kavre, Nepal; ${ }^{3}$ Department of Community Medicine, Kathmandu University School of Medical \\ Science
}

Correspondence to: Pankaj Pant, Department of Internal Medicine, Kathmandu University School of Medical Sciences Email: drpant77@hotmail.com

\begin{abstract}
Introduction: Chronic obstructive pulmonary disease (COPD) remains a major public health problem. Many patients suffering from chronic obstructive lungs diseases are of poor economic status, mostly illiterate, therefore has a direct bearing on patient compliance. Tiotropium is a new anticholinergic therapy for chronic obstructive pulmonary disease that differs from ipratropium by its functional relative selectively for musarinic receptor subtypes and which allows single dosing a day. This study presents a cost-effectiveness, efficacy, and side-effects of Ipratropium bromide and Tiotropium in COPD.

Methods: Prospective study was conducted In Kathmandu University Teaching Hospital, between the year 2008 and 2009 in terms of cost-effectiveness, efficacy, and side-effects of Tiotropium and Ipratropium amongst COPD patients.

Results: Tiotropium and Ipratropium were prescribed in total of 57 patients ( 30 in ipratropium bromide and 27 in tiotropium bromide) for the management of COPD among outpatients. There were no significant differences in age, height, weight and baseline lung function parameters ( $\mathrm{FEV}_{1}$ and $\mathrm{PEF}$ ) between the two drugs i.e. ipratropium bromide and tiotropium bromide. Significant improvement in lung function parameters were found in each respective group of drugs after bronchodilator therapy. Tiotropium results in significant reduction of Chronic Obstructive Pulmonary disease exacerbations and significant improvement in quality of life, lung function, and dyspnoea compared to ipratropium. The additional cost to achieve these favorable outcomes was cheaper than Ipratropium bromide. (Nepalese Rs. 7.03 per day for tiotropium as compared to Rs. 9.06 for Ipratropium)

Conclusions: Tiotropium results in significant reduction of chronic obstructive pulmonary disease exacerbations and significant improvement in quality of life, lung function and dyspnoea compared to Ipratropium.
\end{abstract}

Keywords: Chronic obstructive pulmonary disease, ipratropium, tiotropium

\section{Introduction}

Chronic obstructive pulmonary disease (COPD) remains a major public health problem. It is the fourth leading cause of chronic morbidity and mortality in the United States and is projected to rank fifth in 2020 in burden of worldwide, according to a study published by the World Bank /World Health Organization. ${ }^{1}$

Chronic Obstructive Pulmonary Disease is characterized by chronic airflow limitation that is not fully reversible and usually progressive characteristic symptoms include 
chronic and progressive dyspnoea, cough and sputum production, which result in significant impairment in exercise capacity and quality of life. ${ }^{2}$ Worsening lungs function is also associated with frequently increasing disease severity. ${ }^{3}$ This contributes to a more rapid decline in lungs function, ${ }^{4}$ increased mortality and further reductions in quality of life. ${ }^{5}$

COPD is a costly disease. Many patients suffering from chronic obstructive lungs diseases are of poor economic status, mostly illiterate, therefore, it has a direct bearing on patient compliance. In coming years, the burden of COPD will increase as reflected by increasing inpatient and outpatient flow. There is an acute need for more effective treatment options to reduce the burden of this disease for patients, care givers and society. ${ }^{6}$

COPD is a growing problem in developing countries including Nepal. There is a direct relationship between the severity of COPD and the cost of care. ${ }^{7}$ Cost for patient varies across countries because the cost depends on how health care is provided and paid. ${ }^{8}$

Tiotropium is a new anticholinergic therapy for chronic obstructive pulmonary disease that differs from ipratropium by its relative selectively for musarinic receptor subtypes and which allows single dosing a day.

The present study is a prospective study designed to compare efficacy, safety and cost effectiveness of tiotropium bromide and ipratropium bromide in the treatment of COPD.

The efficacies of two drugs were measured with reference to the pulmonary function test based on spirometry. The saftiest of drugs were measured in terms of side effects produced during treatment. The costs of drugs were calculated in terms of cost per day of drugs used by the patient.

\section{Methods}

Prospective study was conducted in Kathmandu University Teaching Hospital, between the year 2008 and 2009 in terms of cost-effectiveness, efficacy, and side-effects of tiotropium and ipratropium amongst COPD patients. The patients with COPD, visiting the out patients department of Dhulikhel hospital, Kathmandu University Teaching Hospital, between December 2008 to June 2009, were selected for the study. Patients were selected from outpatient. Current or exsmokers with relatively stable COPD and a FEV1 e" $70 \%$ of the predicted normal were selected for the study. Patients were also required to be aged $>40$ years. Patients with the history of asthma requiring regular supplemental oxygen and patients with recent upper respiratory tract infection or a significant disease other than COPD were excluded. Patients were selected according to the selection criteria. Fifty seven (57) consecutive patients who fulfilled the inclusion criteria were further divided in tiotropium group and ipratropium group: 27 in tiotropium group and 30 in ipratropium group. Patients received $18 \mu \mathrm{g}$ triotrpium rotacap once daily and other received $40 \mu \mathrm{g}$ of ipratropium rotacap four times a day.

After taking informed consent, the patients were enrolled for the study. Patients were followed up for 6 month. The tool used was a set of prepared questionnaire and spirometry for each patient whose diagnosis was based on clinical evidences of the diagnostic test reports. All the patients were asked for information as specified in the questionnaire. The spirometry of all the patients before and after using of tiotropium and ipratropium were taken mainly for the improvement in lung function test and testing the efficacy of two drugs. Direct cost of tiotropium bromide (TIOVA ${ }_{-}^{\circledR}$ and ipratropium bromide (IPRAVENT ${ }^{\circledR}$ ) inhaler cost per day were calculated in Nepalese Rupees (NRs).

The data obtained after structured questionnaire and from medical records were compiled. The compiled data were analyzed using SPSS-11.5 and the graphs were plotted using Microsoft Excel. Both descriptive and inferential statistics were used to show the frequency of occurrence and to establish the relationship between the variables.

\section{Results}

\section{Demographic characteristics}

Out of 57 Patients using two different drugs, Brahmin, Chhetri and Newar constitute equal proportion of the population (22.8\%) while Magar (21.05\%) and other cast groups like Giri, Pariyar, Lohala, Gurung, Sherpa and Singh constitute the least percentage $(10.5 \%)$ of the study population as (Table 1). It was found that most of the patients were literate in both of the drug groups (66.67\%) and only one third $(33.33 \%)$ of the patients were illiterate. The occupational characteristics showed that farmers and the housewives constituted majority of population. Service, business and other occupations like driver and daily wage (non-agriculture) were recorded during the entire study

The mean age of the COPD patients was found to be $63 \pm$ 7.6 ranging from 49 to 78 for tiotropium bromide users and $61.8 \pm 8.3$ with a range of 48 to 78 for the ipratropium bromide users. The distribution of the age in both groups seems to be similar as there is no difference between both of the ages (p-value 0.486). 
Role of tiotropium in chronic obstructive pulmonary disease exacerbation

Table 1: Demographic Characteristics of the Patients

\begin{tabular}{|c|c|c|c|}
\hline Variables & Characteristics & Tiotropium bromide users $(n=27)$ & Ipratropium bromide users $(\mathrm{n}=\mathbf{3 0})$ \\
\hline \multirow[t]{7}{*}{ Age } & Mean \pm SD & $63.0 \pm 7.6$ & $61.8 \pm 8.3$ \\
\hline & Age groups & & $\mathrm{p}=0.486$ \\
\hline & $40-49$ & 1 & 2 \\
\hline & $50-59$ & 10 & 12 \\
\hline & $60-69$ & 11 & 11 \\
\hline & e"70 & 5 & 5 \\
\hline & Total & 27 & 30 \\
\hline \multirow[t]{3}{*}{ Gender } & Female & 17 & 16 \\
\hline & Male & 10 & 14 \\
\hline & Total & 27 & 30 \\
\hline \multirow{6}{*}{ Ethnicity } & Brahmin & 8 & 5 \\
\hline & Chhetri & 7 & 6 \\
\hline & Newar & 5 & 8 \\
\hline & Magar & 5 & 7 \\
\hline & Other & 2 & 4 \\
\hline & Total & 27 & 30 \\
\hline \multirow[t]{3}{*}{ Education } & Literate & 20 & 18 \\
\hline & Illiterate & 7 & 12 \\
\hline & Total & 27 & 30 \\
\hline \multirow[t]{6}{*}{ Employment } & Farmer & 8 & 9 \\
\hline & Housewives & 6 & 11 \\
\hline & Service & 4 & 2 \\
\hline & Business & 4 & 6 \\
\hline & Other & 5 & 2 \\
\hline & Total & 27 & 30 \\
\hline
\end{tabular}

Altogether, 84.21 percent of the patients were smokers with 47.37 percent as currently smoking and 36.82 as ex-smokers while 15.78 percent of the patients were non smokers in both of the groups. Among the patients using tiotropium bromide, 85.19 percent were smoker and only 14.81 percent as non smokers. Around the same proportion of the patients using ipratropium bromide were smokers (83.3\%) and 16.7 were found to be non smokers (Fig. 1).

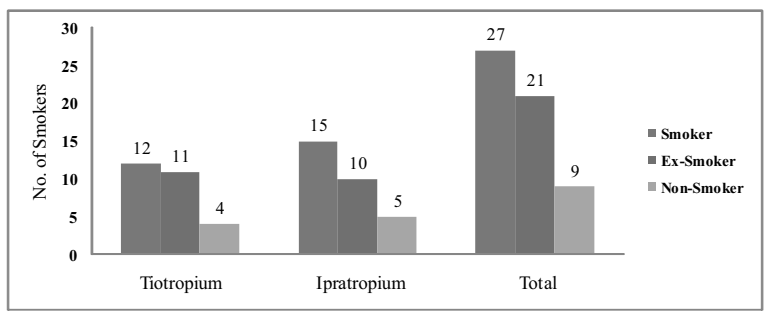

Fig. 1: Smoking behavior of the patients

Users' behavior is also a determinant factor to the drug effectiveness. Patients using ipratropium bromide are less regular on taking the medicine. Out of 30 patients, only 22 patients were regular users. Similarly, among the 27 patients consuming tiotropium bromide, only 3 were not regular for their medicine.

Table 2: Distribution of the Patients according to the Compliance of the Drug

\begin{tabular}{|c|c|c|c|c|c|c|c|}
\hline \multirow{2}{*}{ Compliance } & \multicolumn{4}{|c|}{ Tiotropium } & \multicolumn{3}{|c|}{ Ipratropium } \\
\hline & Malc & & Fen & & Mal & & Female \\
\hline & Yes & No & Yes & No & Yes & No & Yes No \\
\hline & 16 & 1 & 8 & 2 & 12 & 4 & 104 \\
\hline
\end{tabular}

The compliance of the drug is affected by various factors. Time and frequency as well as the price are the major factors determining the compliance. In the case of tiotropium bromide, the possibility of disobedient on taking the drug remains less because the drug is needed to take once a day. Patients usually do not forget to take once. But in the case of ipratropium bromide, the case is different. Patients need to focus their attention to take their drug for four times a day and sometimes the regularity gets break up (Table 2).

Cost is another factor underlying the compliance. Tiotropium bromide with the brand name (TIOVA) costs 211 NRs per pack that contains 30 capsules. Looking at first, it is 
expensive to purchase but when we calculate the price, then the cost per day is only NRs 7.03 per day. The next drug, ipratropium bromide (with the drug name (IPRAVENT) per pack can be purchased on NRs 68 that also contains 30 capsules but that is required to take four times a day. Calculating the cost, it is only available in NRs 9.06 per day.

Among the users of tiotropium bromide, fewer side effects were seen than among ipratropium bromide users. Urinary retention (3), constipation (4), dryness of mouth (13), confusion (1) were the prominent side effects seen to the users of tiotropium bromide. Dryness of mouth is only the largest side effect (Fig. 2).

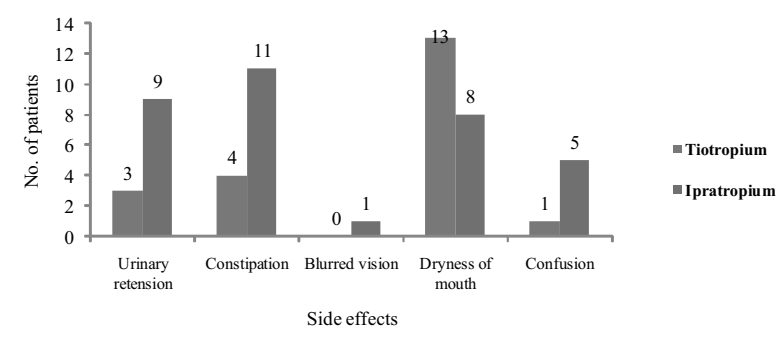

Fig. 2: Distribution of the side effects according to the drugs

Ipratropium bromide has larger scale of side effects. The prominent side effects were urinary retention (9), constipation (11), blurred vision (1), dryness of mouth (8) and confusion (5).

Four kinds of comparisons have been made in order to find the differences between tiotropium and ipratropium. The lung function $\left(\mathrm{FEV}_{1} \& \mathrm{PEF}\right)$ before and after administration (15 days) of drugs were measured in each patient. The null hypothesis in these the cases would be that there is no difference in lung function between these drugs before and after administration of the $\mathrm{FEV}_{1}$ and PEF levels contains no differences. Alternative hypotheses are, then established for the difference between the drugs.

- $\quad \mathrm{FEV}_{1}$ before and $\mathrm{FEV}_{1}$ after the drug administration of tiotropium bromide

- $\quad \mathrm{FEV}_{1}$ before and $\mathrm{FEV}_{1}$ after the drug administration of ipratropium bromide

- $\quad$ PEF before and PEF after the drug administration of tiotropium bromide

- $\quad$ PEF before and PEF after the drug administration of ipratropium bromide

Table 3: Comparison of lung function $\left(\mathrm{FEV}_{1} \& \mathrm{PEF}\right)$ before and after administration of drugs

$\begin{array}{lllll}\begin{array}{l}\text { Differences of } \\ \text { measures }\end{array} & \mathrm{X} & \mathrm{SEM} & \mathrm{t} & \mathrm{Sig} .(2 \text {-tailed) } \\ \begin{array}{l}\text { Tiotropium } \mathrm{FEV}_{1} \\ \text { before -FEV } \text { after }_{1}\end{array} & 0.50 & 0.069 & 5.60 & \mathrm{p}=0.001 \\ \begin{array}{l}\text { Tiotropium PEF } \\ \text { before - PEF after }\end{array} & 0.40 & 0.075 & 4.28 & \mathrm{p}=0.001 \\ \begin{array}{l}\text { Ipratropium FEV } \\ \text { before - FEV }{ }_{1} \text { after }\end{array} & 0.30 & 0.077 & 3.69 & \mathrm{p}=0.001 \\ \begin{array}{l}\text { Ipratropium PEF } \\ \text { before- PEF after }\end{array} & 0.30 & 0.068 & 3.87 & \mathrm{p}=0.001\end{array}$

The t-statistics analysis shows significant differences between before and after the use of the drug in the variables tested (within the drugs) at $95 \%$ confidence interval where the distribution follows the normality (Table 3). T-statistics shows significant differences with respective p-values. As the t-statistics of tiotropium bromide and ipratropium bromide have the higher values in both of the cases, hence they are effective drugs to use.

The mean percentage increment in $\mathrm{FEV}_{1}$ \& $\mathrm{PEF}$ before and

Table 4: Percent increase in $\mathrm{FEV}_{1}$ and PEF level after administration of drug

\begin{tabular}{|c|c|c|c|c|c|c|c|}
\hline \multirow{3}{*}{ Measures } & & \multicolumn{3}{|c|}{ Paired Differences (\%) } & \multirow{3}{*}{$\mathrm{t}$} & \multirow{3}{*}{$\mathrm{df}$} & \multirow{3}{*}{$\begin{array}{l}\text { Sig.(2- } \\
\text { tailed) }\end{array}$} \\
\hline & \multirow[t]{2}{*}{$\bar{X}$} & \multirow[t]{2}{*}{ SEM } & \multicolumn{2}{|c|}{$\begin{array}{l}95 \% \text { CI of the } \\
\text { Difference }\end{array}$} & & & \\
\hline & & & Lower & Upper & & & \\
\hline $\begin{array}{l}\text { increase of the } \mathrm{FEV}_{1} \text { after } \\
\text { tiotropium Percent increase of the } \mathrm{FEV}_{1} \\
\text { after ipratropium }\end{array}$ & 8.83 & 3.5 & 0.67 & 15.19 & 3.74 & 26 & $\mathrm{p}=0.033$ \\
\hline $\begin{array}{l}\text { increase of the PEF after } \\
\text { tiotropium Percent increase of the PEF } \\
\text { after ipratropium }\end{array}$ & 3.95 & 2.02 & 0.68 & 9.00 & 3.69 & 26 & $\mathrm{p}=0.024$ \\
\hline
\end{tabular}


Role of tiotropium in chronic obstructive pulmonary disease exacerbation

drug administration in each of drug was calculated separately. There is significant difference between percentage increment in $\mathrm{FEV}_{1}(\mathrm{p}=0.033) \& \operatorname{PEF}(\mathrm{p}=0.024)$ level between tiotropium and ipratropium after administration. Tiotropium has better effect than that of ipratropium, it has better lung function than ipratropium. then ipratropium. ${ }^{12}$ When cost are calculated by severity, the additional cost of toitropium is always offset by saving made through reduces progression and exacerbations.

Age has been negatively associated with both of the parameters. The negative correlation coefficient between

Table 5 : Bivariate Correlation of PEF and $\mathrm{FEV}_{1}$ after Using the Two Drugs

\begin{tabular}{|c|c|c|c|c|c|}
\hline $\begin{array}{l}\text { Tiotropium } \\
\text { bromide }\end{array}$ & $\begin{array}{l}\text { Pearson's } \\
\text { Correlation with } \\
\text { p-values }\end{array}$ & $\begin{array}{l}\text { Age of users } \\
\text { using } \\
\text { Tiotropium }\end{array}$ & $\begin{array}{l}\text { Ipratropium } \\
\text { Bromide }\end{array}$ & $\begin{array}{l}\text { Pearson's } \\
\text { Correlation } \\
\text { with p-values }\end{array}$ & $\begin{array}{l}\text { Age of the users using } \\
\text { Ipratropium Bromide }\end{array}$ \\
\hline $\mathrm{FEV}_{1}$ before & $(p=0.005)$ & $\mathrm{r}=-0.528$ & $\mathrm{FEV}_{1}$ before & $(p=0.025)$ & $\mathrm{r}=-0.413$ \\
\hline PEF before & $(p=0.106)$ & $\mathrm{r}=-0.318$ & PEF before & $(p=0.666)$ & $\mathrm{r}=-0.047$ \\
\hline $\mathrm{FEV}_{1}$ after & $(p=0.028)$ & $\mathrm{r}=-0.422$ & $\mathrm{FEV}_{1}$ after & $(p=0.016)$ & $\mathrm{r}=-0.429$ \\
\hline PEF after & $(p=0.189)$ & $\mathrm{r}=-0.261$ & PEF after & $(p=0.966)$ & $\mathrm{r}=-0.008$ \\
\hline
\end{tabular}

The correlation between age of the patients and lung function test parameters $\left(\mathrm{FEV}_{1} \& \mathrm{PEF}\right)$ before and after administration of tiotropium and ipratropium were found as shown in Table 5. In all cases, as correlation coefficient (r) is found to be negative, we can conclude that as the age of the patients increases, their lung function decreases.

\section{Discussion}

Tiotropium and ipratropium were prescribed in total of 57 patients (30 in ipratropium bromide and 27 in tiotropium bromide) via DPI (Rotacap) for the management of COPD. There were no significant differences in age, height, weight, $\mathrm{BMI}$ and baseline lung function parameters $\left(\mathrm{FEV}_{1}\right.$ and $\left.\mathrm{PEF}\right)$ between the two groups. Significant improvement in lung function parameters were found in both respective groups of drugs after bronchodilator therapy. However comparing the improvement of the lung function parameters between two drugs, there was a significant difference between them ( $p=0.033$ for $\mathrm{FEV}_{1}$ and 0.024 for PEF respectively). Patients using ipratropium bromide were more prone to side effects like constipation, blurred vision, confusion and then dryness of mouth. The side effect more prone to tiotropium was dryness of mouth than ipratropium bromide. The utilities values were derived independently from the efficacy data; however they did not represent the efficacy observed in the clinical trials data. ${ }^{9-11}$

The compliance recorded was higher in case of tiotropium bromide. The cost of treatment with tiotropium bromide was found to be much lesser than with of ipratropium bromide. The Oostenbrink study compared costs in the Netherland and Canada, and found that in the Netherland tiotropium was the least expensive treatment, followed by salemeterol age and the parameters in both of the groups show that with the increase in age, the susceptibility of disease increases. From this we can conclude that as the age of the patients increases their lung function decreases.

\section{Conclusions}

Tiotropium in a dose of $18 \mu \mathrm{g}$ inhaled once a day via DPI is more effective and safe than $40 \mu \mathrm{g}$ ipratropium via DPI four times daily in improving lung function over fifteen days. The safety profile of tiotropium was greater than that of ipratropium with exception of dryness of mouth. The cost of treatment with tiotropium is less than that of ipratropium. These data support the use of tiotropium as a first line treatment of patients with airflow obstruction due to COPD

\section{References}

1. Global Initiative for Chronic Obstructive Lungs Diseases (GOLD). Global Strategy for Diagnosis, Management, and Prevention of COPD. [online]. Available from: URL:http://www.Goldcopd.org.

2. Ray Gani, Jnae Griffin, Steve Kelly, Maureen RuttenVan Molken, et al. Economic analyses comparing tiotropium with ipratropium or salmeterol in UK patient with COPD. Primary Care Respiratory Journal. 2010;19(1):68-74.

3. Amderson F, Borg S, Jansson SA, et al. The costs of exacerbations in chronic obstructive pulmonary disease (COPD). Respir Med. 2002;96:700-8.

4. Donald son GC, Seemungal TA, Bhowmik A, et al. Relationship between exacerbation frequency and lung function decline in chronic obstructive pulmonary 
disease. Thorax. 2002;57:847-52.

5. Seemungal TA, Donaldson GC, Bhowmik A, et al. Time course and recovery of exacerbations in patients with chronic obstructive pulmonary disease. Am J Respir Crit Care Med. 2000;161:1608-13.

6. Berr RG, Bourbeau J, Camargo, et al. Tiotropium for stable chronic obstructive pulmonary diseases: A meta - analysis. Thorax. 2006;61(10):854-62.

7. Chapman KR, MAnnino DM, Soriano JB, Vermeire PA, Buist AS, Thun MJ, et al. Epidemiology and costs of chronic obstructive pulmonary diseases. Eur Respir J. 2006;27:188-207.

8. Jansson SA, Andersson F, Borg S, Ericsson A, Jonson E, Lundback B. Costs of COPD in Sweden according to diseases severity. Chest. 2002;122:1994-2002.

9. Brusasco V, Hodder R, Miravitlles M, et al. Health outcomes following treatment for six months with once daily tiotropium compared with twice daily salmeterol in patients with COPD. Thorax. 2003;58:399-404.

10. Vincken W, van Noord JA, Greefhorst AP, et al. Improved health outcomes inpatients with COPD during 1 years treatment with tiotropium. Eur Respir J. 2002;19:209-16.

11. Casaburi R, Mahler DA, Jones PW, et al. A long-term evaluation of once-daily inhaled tiotropium in chronic obstructive pulmonary disease. Eur Respir J 2002;19:217-24.

12. Oostenbrink JB, Rutten-van Mölken MPMH, Monz BU, et al. Markov model to assess the cost-effectiveness of bronchodilator therapy in COPD patients in different countries. Value Health 2005;8:32-46. 